\title{
Understanding Nonnative University EFL Teachers' Professional Anxiety and Their Emotion Regulation Strategies
}

\author{
Bo Yang ${ }^{1 \& 2}$ \\ ${ }^{1}$ Xinhua College, Ningxia University, Yinchuan, China \\ ${ }^{2}$ Faculty of Education and Arts, School of Humanities and Social Science, The University of Newcastle, New \\ South Wales, Australia \\ Correspondence: Bo Yang, Xinhua College, Ningxia University, Yinchuan, China. E-mail: b.yang@uon.edu.au
}

Received: March 25, $2021 \quad$ Accepted: April 29, $2021 \quad$ Online Published: May 14, 2021

doi:10.5539/ijel.v11n3p87 URL: https://doi.org/10.5539/ijel.v11n3p87

\begin{abstract}
Based on an in-depth semi-structured interview method, this study explored sources of nonnative university English as a Foreign Language (EFL) teachers' professional anxiety and relevant emotion regulation strategies in a Chinese context. Participants mostly suffered from academic promotion anxiety, followed by research anxiety, teaching anxiety, and anxiety about English language proficiency and knowledge. To overcome this negative emotion, participants adopted two families of emotion modifications: response-focused regulation strategies including coping, expressive suppression, and communication, as well as antecedent-focused regulation strategies comprising cognitive reappraisal and distraction, with the former outweighing the latter. Findings revealed the complexity of nonnative university EFL teachers' professional anxiety and cultural differences in emotion regulation strategies.
\end{abstract}

Keywords: emotion regulation strategies, nonnative university EFL teachers, professional anxiety

\section{Introduction}

As an emotional practice (Hargreaves, 1998, 2001), teaching is imbued with emotional interaction between learners and teachers (Dewaele et al., 2018). Nevertheless, emotional research in the educational domain has mostly been developed from the perspective of learners (Arnold, 1999), leaving teacher emotions largely neglected (Dewaele et al., 2018; Mercer \& Kostoulas, 2018). It was not until the mid-1970s that teachers were considered to have mental lives (Freeman, 2002). Research on teacher emotions has gained attention since the turn of the current century (Arnold, 1999). Teacher emotions are of great importance in teachers' instructional effectiveness (Sutton, 2005), burnout (Chang, 2009), professional identity (Lee et al., 2013) as well as students' emotional experiences (Becker et al., 2014), and consequently students' learning achievement (Frenzel, 2014).

Most empirical research on teacher emotions has been conducted in general education (Lee et al., 2017), leaving emotional variables the least understood area for second language acquisition (SLA) researchers (Scovel, 2001). Compared with the emotional experience of teachers in other subjects, concern about nonnative EFL teachers' emotions is particularly important due to the nature of the course itself and teachers' tremendous anxiety caused by stressful teaching practices (Lee \& Lew, 2001). To date, very little is known about nonnative EFL teachers' emotions (Braine, 2010); particularly their anxiety (Tum, 2012) and how they use relevant emotion regulation strategies to regulate anxiety in professional development.

Emotions are characterised by cultural differences. Teacher emotion is a product of cultural, social, and political relations (Zembylas, 2005). In a similar vein, emotion regulation is moderated by different cultural norms (Sutton \& Harper, 2009). Therefore, research on emotions needs to consider Chinese society for its cultural specificities (Yik, 2010). To date, most studies on teacher emotion and teacher emotion regulation strategies have been conducted from western perspectives, leaving the Chinese context largely unexplored.

The present study was thus designed to explore sources of nonnative university EFL teachers' professional anxiety and how they regulate this negative affective variable in the Chinese context. To best capture the complexity of nonnative university EFL teachers' anxiety, we need to move beyond the teaching or classroom context and consider additional potential anxiety-provoking factors in teachers' professional development. 


\section{Literature Review}

\subsection{Nonnative EFL Teachers' Anxiety}

Anxiety is associated with subjective and negative feelings, such as uneasiness, worry, self-doubt, and frustration (Arnold \& Brown, 1999). Teaching anxiety concerns activities as a teacher and other classroom and school-related activities (Buitink \& Kemme, 1986). The phenomenon of globalisation has significantly accelerated demand for English language teaching, which is largely filled by nonnative English-speaking teachers, who account for at least $80 \%$ of all English teachers worldwide (Braine, 2010). Compared with native teachers, nonnative language teachers experience a strong sense of anxiety in attaining the same language proficiency (Greis, 1985) since language learning is without exception, a never-ending process (Mousavi, 2007).

Ground-breaking research on nonnative EFL teachers' anxiety was carried out by Horwitz (1996), who pointed out that the study of anxiety in SLA has predominantly been focused on learners' foreign language learning anxiety, and corresponding research on teachers' anxiety is largely missing. Although EFL teachers are high-level speakers of the target language, they parallel the anxiety experienced by language learners when they frequently feel inadequate in the target language, and when such feelings are inconsistent with a realistic evaluation of competence (Horwitz, 1996). To measure teachers' anxiety in using the target language in classroom instruction, Horwitz (2008) developed an 18-item Teacher Foreign Language Anxiety Scale (TFLAS) with a 5-point Likert scale ranging from "strongly disagree" to "strongly agree". However, due to insufficient concern about EFL teachers' emotions, very few quantitative studies have explored nonnative EFL teachers' anxiety by using the TFLAS (Mousavi, 2007).

Limited studies on EFL teachers' anxiety have been conducted in teaching or classroom instruction contexts, mainly by exploring the factors and influences provoking EFL teachers' anxiety, as well as the relationship between teaching anxiety and certain factors. Regarding sources of EFL teachers' anxiety, teachers' internal variables including a sense of inferiority about target language proficiency (Horwitz, 1996; Klanrit \& Sroinam, 2012; Tang, 1997), spontaneous language use, continuation of anxiety experienced as foreign language learners (Horwitz, 1996), lack of self-confidence, class preparation (Yoon, 2012), and classroom management (Mosaddaq \& Barahmeh, 2016) have been identified. Besides, students' influence comprising disruptive behaviours (Horwitz, 1996) and low English proficiency (Kongchan \& Wareesiri, 2008) have been added.

Research has revealed that anxiety reduces EFL teachers' frequency of using the target language in classroom instruction (Horwitz, 1996) and their teaching effectiveness (Williams, 1991), while it also increases job burnout (Aslrasouli \& Vahid, 2014). It is believed that teaching and training experience is negatively correlated with the level of EFL teachers' anxiety (Machida, 2016). Due to the great number of female teachers, gender has been examined, but was found to have no significant effects on EFL teachers' anxiety (Aslrasouli \& Vahid, 2014), in contrast to corresponding studies in other disciplines where female teachers have been found to display higher levels of anxiety than their male peers owing to physiologically based phenomena (Morton et al., 1997).

\subsection{Emotion Regulation Strategies}

Emotion regulation refers to "the processes by which individuals influence which emotions they have, when they have them, and how they experience and express these emotions" (Gross, 1998b, p. 275). Gross (1998a) identified two emotion regulatory processes that bring about different adaptive consequences: antecedent-focused emotion regulation occurring before emotions are generated and response-focused emotion regulation happening after emotions are triggered.

According to Gross (1998a), antecedent-focused modulation includes four specific emotion regulation strategies: situation selection, referring to approaching a desirable or avoiding an undesirable situation to regulate emotions; situation modification, involving efforts to alter a situation to modify the emotional impact; attention deployment, concerning directing attention towards or away from a given situation to regulate emotions; and cognitive change, regarding one's appraisal of a situation to alter its emotional impact. Response-focused emotion regulation covers a variety of types, including "strategies that intensify, diminish, prolong, or curtail ongoing emotional experience, expression, or physiological responding" (Gross, 1998a, p. 225). In a follow-up study, Gross and John (2003) developed a 10-item Emotion Regulation Questionnaire with a 7-point Likert-type scale ranging from "strongly disagree" to "strongly agree" to measure participants' tendency to regulate their emotions in two ways: cognitive reappraisal and expressive suppression. As an example of the antecedent-focused regulation strategy, cognitive reappraisal refers to reconstructing an emotion-eliciting situation to modify its emotional impact (Gross \& John, 2003). As a form of response-focused modulation, expressive suppression involves inhibiting emotion-expressive behaviours (Gross, 1998a). 
Gross's model of emotion regulation has inspired many researchers to advance the understanding and operationalisation of emotion regulation and emotion regulation strategies. Based on a semi-structured interview process, Sutton (2004) reported that teachers used different preventative (e.g., modifying situations, attention deployment, and cognitive change) and responsive strategies (e.g., behavioural and cognitive strategies) to regulate their emotions. Yin (2016) identified three categories and seven emotion regulation strategies: surface acting, comprising pretending and restraining; deep acting, involving refocusing, reframing, and separating; and genuinely expressing, which consists of releasing and outpouring. The surface and deep acting categories were consistent with Gross's (1998a) conceptualisation of response-focused and antecedent-focused emotion regulation strategies, respectively.

Teachers are emotional beings (Zembylas, 2005). Research has proven that teacher emotion regulation promotes teaching effectiveness (Sutton, 2005), correlates with job burnout (Lavy \& Eshet, 2018), and helps teachers fulfil their professional goals and attain satisfaction (Yin, 2016). However, exploration of teacher emotion regulation is still in its infancy, and much research needs to explore its basic processes, cultural context, and classroom implications (Sutton \& Harper, 2009).

\section{Research Questions}

The current study aims to address the following research questions:

(1) What are the sources of nonnative university EFL teachers' professional anxiety in a Chinese context?

(2) How do nonnative university EFL teachers regulate their professional anxiety in a Chinese context?

\section{Method}

\subsection{Participants}

The maximum variation sampling proposed by Creswell (1998) was adopted to recruit participants in this study, achieving exploration of the complex world presented by multiple perspectives of individuals (Creswell, 2012). Initiated in 1995 by China's Ministry of Education, Project 211 is a project aiming at strengthening about 100 national key universities and colleges for the 21 st century. To enhance the generalisability of research findings via participants' broad diversity, the ten EFL teacher participants involved in the semi-structured interviews were recruited from five key and five non-key universities in China. Out of the total interview participants, two were male, eight were female, eight had a master's qualification, one was a $\mathrm{PhD}$ candidate, one held a $\mathrm{PhD}$ qualification, one was an assistant, seven were lecturers, one was an associate professor, and one was a professor. The minimum years of teaching among interview participants was two, and the maximum was 26 . Table 1 below demonstrates interview participants' demographic information.

Table 1. Participants' demographic information

\begin{tabular}{lllllll}
\hline Teacher & Gender & Age & School & Teaching Years & Qualification & Title \\
\hline T1 & M & 33 & Non-211 & 7 & Master & Lecturer \\
T2 & F & 49 & 211 & 26 & Master & Associate Professor \\
T3 & F & 33 & 211 & 8 & PhD candidate & Lecturer \\
T4 & F & 28 & Non-211 & 2 & Master & Assistant \\
T5 & M & 37 & 211 & 11 & Master & Lecturer \\
T6 & F & 36 & 211 & 11 & Master & Lecturer \\
T7 & F & 47 & 211 & 23 & PhD & Professor \\
T8 & F & 34 & Non-211 & 6 & Master & Lecturer \\
T9 & F & 35 & Non-211 & 8 & Master & Lecturer \\
T10 & F & 37 & Non-211 & 9 & Master & Lecturer \\
\hline
\end{tabular}

\subsection{Instrument}

An in-depth semi-structured interview process was adopted to collect data. Interview participants were asked to report their anxiety of being an EFL teacher or in a professional context and to summarise emotion regulation strategies they had adopted to overcome their professional anxiety.

\subsection{Data Collection and Analysis}

The 40-45 minutes semi-structured interviews were conducted in the interviewees' native language, Chinese, on days and times that were favourable for participants, and permission was sought to audio record the interviews. The thematic analysis (i.e., familiarising with data, generating initial codes, searching for themes, reviewing 
themes, defining and naming themes, and producing a report) proposed by Braun and Clarke (2006), as well as the three coding stages (i.e., selective coding, axial coding, and open coding) developed by Strauss and Corbin (1998), were utilised to analyse the semi-structured interview data.

\section{Results}

\subsection{Participants' Professional Anxiety}

As can be seen from Table 2, regarding sources of professional anxiety, all ten interview participants, including the newly appointed professor participant, reported tremendous amounts of anxiety caused by academic promotion. Participants from key universities were more likely to suffer from this kind of anxiety since requirements for academic promotion at these universities were more strict and higher than those at non-key universities. Besides, the importance of academic promotion meant more for teacher participants' professional development than their desire for increased income.

The new requirement for academic promotion at my university is too demanding to meet. It seems that I am in a dilemma where on the one hand, the application for promotion to associate professor requires papers and research work; on the other hand, many journals have unwritten rules for authors' professional title (e.g., associate professor or $\mathrm{PhD}$ ), and many research projects only offer opportunities to candidates who are at least associate professors. Whenever I think about that I would retire as a lecturer rather than an associate professor or a professor, I cannot sleep, and I doubt my qualification for being an English teacher. (T6)

Table 2. Sources of participants' professional anxiety

\begin{tabular}{lll}
\hline Category & Coding Sources & References \\
\hline Academic promotion & 10 & 29 \\
Research work & 10 & 22 \\
Teaching & 6 & 13 \\
Language proficiency and knowledge & 3 & 7 \\
\hline
\end{tabular}

Following anxiety about academic promotion, the great pressure of research work was complained about by all ten participants. It is noteworthy to see that participants had difficulties balancing teaching and research, which made research work more title-promotion-driven.

As a novice EFL teacher, the heavy amount of teaching work (18 periods per week) makes me fatigued. Besides, I have to undertake some administrative duties and student services, which limit my time and energy to do research work. However, to meet the requirement of the application for promotion to lecturer, I must strive for it. No publication, no promotion. (T4)

Teachers' teaching anxiety was reported to be the third provoking factor, and was more influential for novice participants who reported a lack of teaching experience. However, against a background of educational informationisation and artificial intelligence, teaching anxiety relating to new teaching reform was mentioned more by older EFL teacher participants.

I remembered due to the lack of teaching experience, I worried about my teaching effectiveness in the first two years of my teaching career. Later, the more I teach, the less teaching anxiety I have. However, the new artificial intelligence teaching reform makes me upset because compared with young teachers, the older teachers are not adept at learning new techniques and skills relating to the educational informationisation. For the first time in my teaching career, I have no idea how to teach my students. (T2)

Anxiety about language proficiency and knowledge is not absent for EFL teachers since participants expressed unwillingness to be observed during their teaching process.

Our university encourages us to go to our colleagues' English classes even without notice in advance, which makes me extremely uncomfortable. I perform confidently and effortlessly when no one comes into my class, but I feel anxious about making mistakes in front of my peers. (T9)

In addition, anxiety about language proficiency is more obvious for participants when trying to publish papers in international journals where a high standard of academic English is required.

Although I have never doubted my ability in teaching English, I was devastated and ashamed about my English language proficiency and knowledge when I got the reviewers' comments from a Social Science 
Citation Index (SSCI) journal. I felt that for many years I had learned and had taught the 'fake' English language. It is very hard for nonnative EFL teachers to publish papers in international journals, particularly in journals with high impact factor. (T3)

\subsection{Participants'Emotion Regulation Strategies}

As presented in Table 3, three types of codes were distinguished based on the interpretation of interview transcripts. Consistent with Gross's (1998a) study, participants employed two families of emotion regulation strategies to regulate their professional anxiety. Regrading antecedent-focused emotion regulation, cognitive reappraisal and distraction involving adjustment of the focus of attention were mostly mentioned.

I always try to reconsider the difficult situation that makes me upset in a more optimistic way. Anyway, there are more solutions than difficulties. If it does not work, practising yoga is an effective way to reduce my anxiety and calm me down. (T10)

Table 3. Coding scheme of participants' emotion regulation strategies

\begin{tabular}{|c|c|c|c|c|}
\hline Selective Coding & Axial Coding & Open Coding & Sources & References \\
\hline \multirow[t]{5}{*}{ Emotion regulation strategies } & Antecedent-focused emotion regulation & Cognitive appraisal & 7 & 20 \\
\hline & & Distraction & 5 & 11 \\
\hline & Response-focused emotion regulation & Coping & 10 & 34 \\
\hline & & Expressive suppression & 7 & 17 \\
\hline & & Communication & 5 & 13 \\
\hline
\end{tabular}

Apart from Gross's (1988a) expressive suppression, the researcher identified other two strategies, including coping, referring to taking actions to deal with emotion-eliciting situations; and communication, involving expressive behaviours to reduce the emotional impact, from participants' interview transcripts as components of response-focused modulation.

I share both my happiness and anxiety relating to work with my family, whose encouragement and support always stimulate me to find possible ways of dealing with anxiety. (T8)

However, not every teacher participant tended to reveal their anxious inner world to others, confirming the strategy of expressive suppression proposed by Gross (1988a). Compared with female participants, male participants were more likely to hide anxious feelings, even from their families or friends.

Rather than talking about my professional anxiety with my family members or friends, I prefer to solve it by myself. Complaining about this negative emotion would do nothing but make them worry about me. (T5)

\section{Discussion}

The first research question dealt with sources of nonnative university EFL teachers' professional anxiety in a Chinese context. Participants exhibited four major categories of anxiety influencing their professional development: academic promotion anxiety, research anxiety, teaching anxiety, and anxiety about English language proficiency and knowledge. Teaching and research are at the heart of universities (Taylor, 2007), and are also important criteria for academic promotion. Nevertheless, there is a recent trend that many universities worldwide have placed greater importance on research productivity in academic promotion (Bai \& Hudson, 2011; Parker, 2008), indicating that research is more highly valued than teaching in higher education (Chen, 2015). The above situation is true in the Chinese context since academic promotion is determined more by research outcomes than teaching effectiveness. However, due to the lack of research knowledge, research environment, research confidence, intrinsic research motivation, and networking (Bai \& Hudson, 2016), Chinese university EFL teachers still have a long way to go to improve their limited research ability. This explains why all participants in this study, regardless of different academic ranks, viewed academic promotion anxiety and research anxiety as the top two anxiety-provoking factors in their professional development.

Following anxiety about academic promotion and research work, participants expressed feeling great pressure from teaching, particularly from undergoing teaching reform of educational informationisation and artificial intelligence. The state-level documents Education Information 10-year Development Plan (2011-2020) issued by the Ministry of Education of the People's Republic of China in 2010 and Next Generation Artificial Intelligence Development Plan published by the State Council of China in 2017 marked that the development and application of educational informationisation and artificial intelligence has become an important direction of 
teaching reform in China. This teaching reform urges Chinese EFL teachers to overcome the heavy teaching workload to redefine their roles and identity and to grasp all technical skills relating to educational informationisation; otherwise, their jobs would be eliminated.

To boost reputation and rankings as well as to compete for government funds, many universities in China require their academics to publish papers in both top-tier national journals indexed in the Chinese Sciences Citation Index (CSCI) and the Chinese Social Sciences Citation Index (CSSCI), and international journals listed in the Science Citation Index (SCI), the Social Sciences Citation Index (SSCI), and the Arts and Humanities Citation Index (A \& HCI) (Zheng \& Guo, 2019). Nevertheless, owing to language barriers (Flowerdew, 1999), heavy teaching workload (Bai \& Hudson, 2011), cross-cultural, cross-linguistic and genre-related differences (Hu \& Cao, 2011), and limited numbers of journals in relevant fields (Peng \& Gao, 2019), participants faced tremendous difficulties in publishing papers with high impact factors. Suffering from the phenomenon of publishing or perishing, participants doubted their English language proficiency and knowledge, despite having confidence in their classroom instruction.

The second research question addressed the emotion regulation strategies adopted by participants in dealing with their professional anxiety. Contrary to Gross's (1998a) argument that antecedent-focused emotion regulation outweighs response-focused emotion regulation for the individual's psychological and physical health, findings in this study revealed that participants were more likely to employ response-focused emotion regulation to overcome professional anxiety. This supports the conclusion reached by Gong et al. (2013) that Chinese teachers use response-focused emotion regulation most frequently, confirming that emotion regulation strategies differ across cultures (Leersnyder et al., 2013).

Regarding response-focused emotion regulation, participants reported coping as the highest strategy, followed by strategies of expressive suppression and communication. Despite huge anxiety relating to various aspects of professional development, Chinese nonnative EFL teachers were optimistic and progressive towards their teaching careers. On the one hand, this is closely related to traditional Chinese culture in coping with difficulties. On the other hand, it indicates that anxiety may have facilitating effects under certain conditions (Young, 1991). Influenced by the traditional collectivistic culture emphasising harmony in groups and discouraging the expression of negative emotions (Wang, 2019) as well as the Chinese face culture (Ji, 2000), participants, particularly male participants, tended to adopt the strategy of expressive suppression rather than communication. This is consistent with findings reported by other scholars in the Chinese context (Gong et al., 2013; Yin, 2016). However, compared with male participants, female participants were more likely to share their unhappy experiences with others, indicating that female teachers were more emotionally expressive.

Apart from response-focused emotion regulation, participants employed two other types of antecedent-focused emotion regulation strategies including cognitive appraisal and distraction to handle their professional anxiety. Participants who adopted a higher level of cognitive appraisal were more likely to take action to cope with difficult situations, strengthening the effectiveness of cognitive appraisal (Yin, 2016). Similar to the function of attention deployment (Gross, 1998a), distraction was revealed by participants to effectively reduce their anxiety by changing the focus to other areas of interest.

\section{Conclusion}

The present study explored sources of nonnative university EFL teachers' professional anxiety in a Chinese context and identified four major anxiety-provoking factors including academic promotion anxiety, research anxiety, teaching anxiety, and anxiety about English language proficiency and knowledge, indicating the complexity of this negative emotion. To overcome their professional anxiety, participants adopted varied emotion regulation strategies in both response-focused and antecedent-focused forms, with the former outweighing the latter. Therefore, this study not only advances the understanding of nonnative EFL teachers' emotions, but particularly depicts their professional anxiety and emotion strategies in regulating professional anxiety in a Chinese context.

However, this research is not without limitations. Although participants were recruited from ten universities in different provinces or cities in China, interview transcripts from this small sample may not fully represent the diversity and complexity of the whole Chinese university EFL teachers' professional anxiety and their emotion regulation strategies. In accordance with current studies on teacher emotion based on qualitative data (Frenzel, 2014), this research employed semi-structured interviews for data collection, which may fail to reflect the real situation since participants may hide their authentic emotions or cater to the researcher. Therefore, future research might need to explore nonnative EFL teachers' professional anxiety and their emotion regulation strategies using a combination of quantitative and qualitative data. 
Despite the limitations, the research findings have important implications. Given that participants reported that academic promotion anxiety caused the highest level of anxiety, and they suffered from imbalances between teaching and research, university policymakers are responsible for creating a favourable research environment, providing more research training opportunities, alleviating teachers' academic promotion and research anxiety via more scientific evaluation systems, and assisting teachers' emotions through psychological guidance. For nonnative university EFL teachers, it is important to stimulate their intrinsic motivation to undertake research work, rather than promotion-driven motivation, comprehensively understand their professional anxiety, and adopt relevant emotion regulation strategies.

\section{References}

Arnold, J. (1999). Affect in language learning. Cambridge University Press.

Arnold, J., \& Brown, H. D. (1999). A map of the terrain. In J. Arnold (Ed.), Affect in language learning (pp. 1-24). Cambridge University Press.

Aslrasouli, S., \& Vahid, M. S. P. (2014). An investigation of teaching anxiety among novice and experienced Iranian EFL teachers across gender. Procedia-Social and Behavioral Sciences, 98, 304-313.

Bai, L., \& Hudson, P. (2011). Understanding Chinese TEFL academics' capacity for research. Journal of Further and Higher Education, 35(3), 391-407. https://doi.org/10.1080/0309877X.2011.569014

Bai, L., \& Hudson, P. (2016). Chinese TEFL teachers' understanding of research significance: A comparative study of two higher education institutions in China. Paper presented at the International Conference on Education and Social Sciences, Singapore. Abstract retrieved from https://eprints.qut.edu.au/113782

Becker, E. S., Goetz, T., Morger, V., \& Ranellucci, J. (2014). The importance of teachers' emotions and instructional behavior for their students' emotions-An experience sampling analysis. Teaching and Teacher Education, 43, 15-26. https://doi.org/10.1016/j.tate.2014.05.002

Braine, G. (2010). Nonnative speaker English teachers: Research, pedagogy, and professional growth. Routledge.

Braun, V., \& Clarke, V. (2006). Using thematic analysis in psychology. Qualitative Research in Psychology, 3(2), 77-101. https://doi.org/10.1191/1478088706qp063oa

Buitink, J., \& Kemme, S. (1986). Changes in student-teacher thinking. European Journal of Teacher Education, 9(1), 75-84. https://doi.org/10.1080/0261976860090109

Chang, M. L. (2009). An appraisal perspective of teacher burnout: Examining the emotional work of teachers. Educational Psychology Review, 21(3), 193-218. https://doi.org/10.1007/s10648-009-9106-y

Chen, C. Y. (2015). A study showing research has been valued over teaching in higher education. Journal of the Scholarship of Teaching and Learning, 15(3), 15-32. https://doi.org/10.14434/josotl.v15i3.13319

Creswell, J. W. (1998). Qualitative inquiry and research design: Choosing among five traditions. Sage.

Creswell, J. W. (2012). Educational research: Planning, conducting, and evaluating qualitative and quantitative research (4th ed.). Pearson.

Dewaele, J.-M, Gkonou, C., \& Mercer, S. (2018). Do ESL/EFL teachers' emotional intelligence, teaching experience, proficiency and gender affect their classroom practice? In J. de D. Martínez Agudo (Ed.), Emotions in second language teaching (pp. 125-141). Springer.

Flowerdew, J. (1999). Problems in writing for scholarly publication in English: The case of Hong Kong. Journal of Second Language Writing, 8(3), 243-264. https://doi.org/10.1016/S1060-3743(99)80116-7

Freeman, D. (2002). The hidden side of the work: Teacher knowledge and learning to teach. Language Teaching, 35(1), 1-13. https://doi.org/10.1017/S0261444801001720

Frenzel, A. C. (2014). Teacher emotions. In E. A. Linnenbrink-Garcia \& R. Pekrun (Eds.), International handbook of emotions in education (pp. 494-519). Routledge.

Gong, S., Chai, X., Duan, T., Zhong, L., \& Jiao, Y. (2013). Chinese teachers' emotion regulation goals and strategies. Psychology, 4(11), 870-877. https://doi.org/10.4236/psych.2013.411125

Greis, N. (1985). Toward a better preparation of the non-native ESOL teacher. In P. Larson, E. L. Judd \& D. S. Messerschmitt (Eds.), On TESOL '84: Selected paper from the 18th annual convention of teachers of English to speakers of other languages (pp. 317-324). TESOL. 
Gross, J. J. (1998a). Antecedent- and response-focused emotion regulation: Divergent consequences for experience, expression and physiology. Journal of Personality and Social Psychology, 74(1), 224-237. https://doi.org/10.1037/0022-3514.74.1.224

Gross, J. J. (1998b). The emerging field of emotion regulation: An integrative review. Review of General Psychology, 2(3), 271-299. https://doi.org/10.1037/1089-2680.2.3.271

Gross, J. J., \& John, O. P. (2003). Individual differences in two emotion regulation processes: Implications for affect, relationships, and well-being. Journal of Personality and Social Psychology, 85, 348-362. https://doi.org/10.1037/0022-3514.85.2.348

Hargreaves, A. (1998). The emotional practice of teaching. Teaching and Teacher Education, 14(8), 835-854. https://doi.org/10.1016/S0742-051X(98)00025-0

Hargreaves, A. (2001). The emotional geographies of teaching. Teachers College Record, 103(3), 1056-1080. https://doi.org/10.1111/0161-4681.00142

Horwitz, E. K. (1996). Even teachers get the blues: Recognizing and alleviating language teachers' feelings of foreign language anxiety. Foreign Language Annals, 29(3), 365-372. https://doi.org/10.1111/j.1944-9720.1996.tb01248.x

Horwitz, E. K. (2008). Becoming a language teacher: A practical guide to second language learning and teaching. Allyn \& Bacon.

Hu, G., \& Cao, F. (2011). Hedging and boosting in abstracts of applied linguistics articles: A comparative study of English- and Chinese-medium journals. Journal of Pragmatics, 43, 2795-2809. https://doi.org/10.1016/j.pragma.2011.04.007

Ji, S. (2000). 'Face' and polite verbal behaviors in Chinese culture. Journal of Pragmatics, 32(7), 1059-1062. https://doi.org/10.1016/S0378-2166(99)00068-5

Klanrit, P., \& Sroinam, R. (2012). EFL teacher's anxiety in using English in teaching in the language classroom. International Journal of Social Science and Humanity, 2(6), 493-496. https://doi.org/10.7763/IJSSH.2012.V2.154

Kongchan, C., \& Wareesiri, S. (2008). Teachers' anxiety about using L2 in EFL classrooms (pp. 317-324). Proceedings of the 16th Annual Korea TESOL International Conference: Responding to a Changing World. Seoul, Korea.

Lavy, S., \& Eshet, R. (2018). Spiral effects of teachers' emotions and emotion regulation strategies: Evidence from a daily diary study. Teaching and Teacher Education, 73, 151-161. https://doi.org/10.1016/j.tate.2018.04.001

Lee, E., \& Lew, L. (2001). Diary studies: The voice of nonnative English speakers in a masters of arts program in teaching English to speakers of other languages. CATESOL Journal, 13(1), 135-149.

Lee, J. C. K., Huang, Y. X. H., Law, E. H. F., \& Wang, M. H. (2013). Professional identities and emotions of teachers in the context of curriculum reform: A Chinese perspective. Asia-Pacific Journal of Teacher Education, 41(3), 271-287. https://doi.org/10.1080/1359866X.2013.809052

Lee, M., Schulz, P. A., \& Vlack, S. (2017). Non-native English-speaking teachers' anxieties and insecurities: Self-perceptions of their communicative limitations. In J. de D. Martínez Agudo (Ed.), Native and non-native teachers in English language classrooms: Professional challenges and teacher education (pp. 119-137). De Gruyter Mouton.

Leersnyder, D. J., Boiger, M., \& Mesquita, B. (2013). Cultural regulation of emotion: Individual, relational, and structural sources. Frontiers in Psychology, 4(55), 1-11. https://doi.org/10.3389/fpsyg.2013.00055

Machida, T. (2016). Japanese elementary school teachers and English language anxiety. TESOL Journal, 7(1), 40-66. https://doi.org/10.1002/tesj.189

Mercer, S., \& Kostoulas, A. (Eds.). (2018). Teacher psychology in SLA. Multilingual Matters.

Ministry of Education of the People's Republic of China. (2010). Education Information 10-year Development Plan (2011-2020). Retrieved May 26, 2020, from http://www.moe.gov.cn/s78/A16/moe_789/201203/t20120331_133414.html

Morton, L. L., Vesco, R., Williams, N. H., \& Awender, M. A. (1997). Student teacher anxiety related to class management, pedagogy, evaluation, and staff relations. British Journal of Educational Psychology, 67(1), 
69-89. https://doi.org/10.1111/j.2044-8279.1997.tb01228.x

Mosaddaq, D., \& Barahmeh, Y. (2016). A study of sources of EFL student teachers' anxiety during their practicum experience. European Journal of Research and Reflection in Educational Studies, 4(1), 16-25.

Mousavi, E. S. (2007). Exploring 'teacher stress' in non-native and native teachers of EFL. English Language Teacher Education and Development, 10, 33-41.

Parker, J. (2008). Comparing research and teaching in university promotion criteria. Higher Education Quarterly, 62(3), 237-251. https://doi.org/10.1111/j.1468-2273.2008.00393.x

Peng, J., \& Gao, X. (2019). Understanding TEFL academics' research motivation and its relations with research productivity. SAGE Open, 9(3), 1-13. https://doi.org/10.1177/2158244019866295

Scovel, T. (2001). Learning new languages: A guide to second language acquisition. Heinle \& Heinle.

State Council of China. (2017). Next generation artificial intelligence development plan. Retrieved May 26, 2020, from http://www.gov.cn/zhengce/content/2017-07/20/content_5211996.htm

Strauss, A., \& Corbin, J. (1998). Basics of qualitative research: Techniques and procedures for producing grounded. Sage.

Sutton, R. E. (2004). Emotional regulation goals and strategies of teachers. Social Psychology of Education, 7(4), 379-398. https://doi.org/10.1007/s11218-004-4229-y

Sutton, R. E. (2005). Teachers' emotions and classroom effectiveness: Implications from recent research. The Clearing House, 78(5), 229-234.

Sutton, R. E., \& Harper, E. (2009). Teachers' emotion regulation. In L. J. Saha \& A. G. Dworkin (Eds.), International handbook of research on teachers and teaching (pp. 389-401). Springer.

Tang, C. (1997). The identity of the nonnative ESL teacher: On the power and status of nonnative ESL teachers. TESOL Quarterly, 31(3), 577-580. https://doi.org/10.2307/3587840

Taylor, J. (2007). The teaching: Research nexus: A model for institutional management. Higher Education, 54(6), 867-884. https://doi.org/10.1007/s10734-006-9029-1

Tum, D. O. (2012). Feelings of language anxiety amongst non-native student teachers. Procedia: Social and Behavioral Sciences, 47, 2055-2059. https://doi.org/10.1016/j.sbspro.2012.06.948

Wang, W. (2019). Chinese perspectives on cultural psychiatry: Psychological disorders in "A Dream of Red Mansions" and contemporary society. Springer.

Williams, L. S. (1991). The effects of a comprehensive teaching assistant training program on teaching anxiety and effectiveness. Research in Higher Education, 32(5), 585-598. https://doi.org/10.1007/BF00992630

Yik, M. (2010). How unique is Chinese emotion? In M. H. Bond (Ed.), The Oxford handbook of Chinese psychology (pp. 205-220). Oxford University Press.

Yin, H. (2016). Knife-like mouth and tofu-like heart: Emotion regulation by Chinese teachers in classroom teaching. Social Psychology of Education, 19(1), 1-22. https://doi.org/10.1007/s11218-015-9319-5

Yoon, T. (2012). Teaching English through English: Exploring anxiety in non-native preservice ESL teachers. Theory and Practice in Language Studies, 2(6), 1099-1107. https://doi.org/10.4304/tpls.2.6.1099-1107

Young, D. J. (1991). Creating a low-anxiety classroom environment: What does language anxiety research $\begin{array}{lllll}\text { suggest? } \quad \text { The } & \text { Modern }\end{array}$ https://doi.org/10.1111/j.1540-4781.1991.tb05378.x

Zembylas, M. (2005). Teaching with emotion: A postmodern enactment. Information Age.

Zheng, Y., \& Guo, X. (2019). Publishing in and about English: Challenges and opportunities of Chinese multilingual scholars' language practices in academic publishing. Language Policy, 18(1), 107-130. https://doi.org/10.1007/s10993-018-9464-8

\section{Copyrights}

Copyright for this article is retained by the author, with first publication rights granted to the journal.

This is an open-access article distributed under the terms and conditions of the Creative Commons Attribution license (http://creativecommons.org/licenses/by/4.0/). 